\title{
Ranolazine: impact on quality of life in patients with stable angina pectoris, results from an observational study in Austria - the ARETHA AT study
}

\author{
Robert Zweiker · Josef Aichinger · Bernhard Metzler · Irene Lang · Eva Wallner · Georg Delle-Karth (D)
}

Received: 18 July 2018 / Accepted: 12 March 2019 / Published online: 8 April 2019

(C) The Author(s) 2019

\begin{abstract}
Summary
Objective Assessment of treatment routine and outcome for ranolazine in clinical practice as second-line treatment for stable angina pectoris (AP).

Design and setting Multicenter, prospective, uncontrolled, non-interventional study at 88 sites including internal specialists, cardiologists, pneumologists, angiologists and primary care practices in Austria.

Participants In this study 292 patients receiving ranolazine in the course of routine treatment on top of beta blockers or calcium channel blockers after failure of first-line therapy.

Main outcome measures Dosage and symptoms were recorded at two visits (at intervals of 12 weeks), complemented by treatment rationale and disease char-
\end{abstract}

\section{R. Zweiker}

Department for Cardiology, Medical University Graz,

Auenbruggerplatz 15, 8036 Graz, Austria

J. Aichinger

2nd Internal Department, Hospital of the Order of

St. Elisabeth Linz, Fadinger Straße 1, 4010 Linz, Austria

\section{B. Metzler}

University Clinic for Internal Medicine, Department

for Cardiology, Medical University Innsbruck,

Anichstraße 35, 6020 Innsbruck, Austria

\section{Lang}

Cardiology, Medical University of Vienna,

Währinger Gürtel 18-20, 1090 Vienna, Austria

\section{E. Wallner}

A. Menarini Pharma GmbH, Pottendorfer

Straße 25-27, 1120 Vienna, Austria

Prim. Prof. Dr. G. Delle-Karth $(\varangle)$

Department for Cardiology, Hospital Hietzing,

Wolkersbergenstraße 1, 1130 Vienna, Austria

georg.dellekarth@wienkav.at

Medical University of Vienna, Vienna, Austria acteristics at baseline. Disease intensity was quantified by angina symptoms, nitrate use and by Canadian Cardiovascular Society (CCS) grading. Quality of life (QoL) was assessed through a 10-grade scale. Data were analyzed by descriptive statistics.

Results Ranolazine was prescribed in order to improve exercise capacity (84.3\%), reduce symptoms $(83.2 \%)$ and reduce AP $(77.1 \%)$. Of the patients $87.3 \%$ received the recommended starting dose of $375 \mathrm{mg}$ and subsequent dose changes were reported for $39.8 \%$. The number of AP attacks was reduced from $5.3 \pm 4.5$ to $0.8 \pm 1.3$ per week; nitrate use was reduced from $3.4 \pm 4.1$ to $0.4 \pm 0.9$ applications per week. Of the patients $94.0 \%$ reported improved exercise capacity and $93.7 \%$ reduced symptoms. For the majority of patients, the CCS improved from grade II to I and QoL improved accordingly. Of the patients 3 experienced adverse drug reactions and $95.5 \%$ continued ranolazine.

Conclusion In this real-world study, ranolazine was shown to be effective, safe and well tolerable. Symptoms of AP were improved, as illustrated by the reduced number of angina attacks, reduced rate of nitrate use, reduced CCS scores and improved QoL.

Keywords Coronary artery disease - Clinical decision making · Drug prescriptions · Quality of life · Antianginal drug

\section{Introduction}

Coronary heart disease (CHD) is a major cause of death in the European population [1]. Treatment of CHD aims at the improvement of mortality and morbidity and at the mitigation of angina symptoms. In addition to treatment improving the prognosis, current guidelines of the European Society of Cardiology (ESC) recommend drugs for symptom control, includ- 
ing beta blockers, calcium channel blockers (CCB) and sublingual nitroglycerin for chest pain management [2]. In cases of failure of the first-line therapy, a switch to the other options (CCB or beta blocker), a combination of both, or the use of other antianginal drugs are to be considered. Second-line drugs can be used as first-line treatment in cases of intolerance or contraindications to both betablockers and CCBs.

This article presents real-life experience on the second-line antianginal drug ranolazine, a piperazine derivative approved for the treatment of chronic stable AP in 2008. Ranolazine causes a reduction in sodium and calcium overload, thus exhibiting antianginal effects by inhibition of the late sodium current in cardiac cells. Ranolazine is therefore expected to improve diastolic tone and oxygen handling during myocardial ischemia [3]. The place in treatment, general properties and guidance for treatment of stable angina is also outlined in the current ESC guidelines [4]. Ranolazine is indicated as an add-on for the symptomatic treatment of stable AP in adult patients who are inadequately controlled or intolerant to firstline antianginal treatment [2]. In Austria, which did not contribute to the pivotal ranolazine studies, failure and/or contraindication or intolerance towards CCBs and beta blockers are required to justify reimbursement of ranolazine by public health insurances [5]. According to registry data, ranolazine is used in up to $20 \%$ of the patients with stable coronary artery disease [6].

This non-interventional study ARETHA AT aimed to improve understanding of the use of ranolazine for the treatment of symptoms in patients with stable AP in routine clinical practice in Austria. Indications for the use of ranolazine are reported, and the findings are put in relation with the results of previous clinical and observational studies. The primary research focus was an evaluation of dose prescription at the screening visit as well as any changes during the course of the study of approximately 12 weeks. The secondary research interests included (1) dose changes, (2) clinical condition for ranolazine prescription including previous therapies, (3) quality of life (QoL), (4) response to ranolazine treatment, and (5) safety and tolerability based on adverse drug reactions and vital signs.

\section{Patients, materials and methods}

\section{Design and conduct of the study}

The ARETHA AT was a non-interventional, non-randomized, uncontrolled post-marketing observational study conducted in a prospective, single country, multicenter format, approved by the responsible independent ethics committee under the code of 27-232 ex $14 / 15$. A screening visit (visit 1) and a subsequent final examination visit (visit 2) approximately 12 weeks later were scheduled at the physician's discretion. This treatment regimen is required for the reimbursement of treatment costs by social insurance [5], although no visit dates were specified by the protocol due to the non-interventional nature of the study. A total of 91 investigators from 88 doctors' offices, including selected primary care doctors and medical specialists (internal specialists, cardiologists, pneumologists and angiologists) were involved. The selection of practices aimed at a balanced representation of health care facilities in Austria. The study was open to a maximum of 720 patients.

Prior to enrolment, patients were informed about the study and data evaluation. Inclusion was clearly separated from all therapeutic and diagnostic procedures, which were carried out according to standard medical care. Open-label ranolazine (sustained release tablets, $375 \mathrm{mg}$, $500 \mathrm{mg}$ or $750 \mathrm{mg}$ ) was prescribed according to the summary of product characteristics (SmPC), which recommend an oral dose of $375 \mathrm{mg}$ twice daily. After 2-4 weeks, the dose should be titrated to $500 \mathrm{mg}$ twice daily and subsequently, according to the patient's response, to a recommended maximum dose of $750 \mathrm{mg}$ twice daily. Adverse events (AEs), such as dizziness, nausea and vomiting may require discontinuation or down-titration of ranolazine to $500 \mathrm{mg}$ or $375 \mathrm{mg}$ twice daily.

All subjects treated with ranolazine according to the SmPC were eligible except for the following exclusion criteria: (1) contraindications according to the SmPC, (2) pregnancy or lactation, (3) use of metformin during the study exceeding $1000 \mathrm{mg} / \mathrm{day}$, (4) ranolazine treatment for more than 2-4 weeks prior to visit 1 , (5) use of over $20 \mathrm{mg}$ daily dose of simvastatin is a contraindication for ranolazine according to the SmPC. Any other concomitant therapies were permissible at the discretion of the treating physician.

The following variables were recorded and analyzed: (1) basic demographic features, (2) date and method of initial diagnosis of coronary artery disease (CAD), (3) risk factors, (4) physical activity, (5) exposure to stress and known trigger factors, (6) blood pressure and heart rate measured according to local routine, (7) disease activity according to the Canadian Cardiovascular Score (CCS), (8) QoL by Likert scale [7] recorded separately by physicians and patients, (9) comorbidities, (10) concomitant medications, (11) ranolazine therapy including dose changes and continuation decisions, (12) AE recording.

\section{Assessment of safety and tolerability}

Any medically undesirable experiences including abnormal laboratory data, which occurred after the administration of ranolazine were considered as AEs. If the relationship to ranolazine was not classified as unrelated by the respective investigator, the $\mathrm{AE}$ was regarded as an adverse drug reaction (ADR). The AEs and ADRs were classified as severe if they resulted in death, were life-threatening, required or prolonged hospitalization, in persistent or significant disabilities 
or incapacities, led to congenital anomalies or birth defects or consisted of another medically important condition. Furthermore, ADRs were classified with respect to the intensity as mild, moderate or severe. All AEs were documented and reported in accordance with all applicable legislation and regulation but only ADRs, coded by Medical Dictionary for Regulatory Activities (MedDRA, www.meddra.org), were considered in this study.

\section{Statistical methods}

Due to the observational nature of this study, no formal calculation of sample size was carried out. The maximum number of 720 participants was defined for organizational reasons and is not related to any scheduled statistical procedures. Statistical analyses were carried out using the analysis software MedCalc $^{\circledR}$ 16.8.4 (MedCalc Software, Ostend, Belgium) and Microsoft Excel ${ }^{\circledR}$ 2010. The only analysis set comprised all eligible patients who took at least one dose of the study medication and for whom at least partial data were documented. Data were analyzed by means of descriptive statistics, including absolute and relative frequencies, sample size $(n)$, minimum (min), maximum (max), arithmetic mean $(\mu)$, standard deviation (SD) and median. Subgroups were formed post hoc by patient characteristics and compared in an exploratory fashion. In the running text, continuous variables are characterized by arithmetic mean \pm SD. Where appropriate, the Wilcoxon signed rank test was used to test selected changes from visit 1 to visit 2 for significance. All data were analyzed as observed without imputation of missing values. Concomitant medication was summarized by the Anatomical Therapeutic Chemical Classification System, level 2 (ATC2).

\section{Results}

\section{Demographics and medical history}

A total of 292 persons participated in visit 1 and 289 $(99.0 \%)$ in visit 2. Of the patients $162(55.5 \%)$ were male, mean age was $73.6 \pm 10.6$ years. Table 1 shows selected demographic and baseline characteristics. Of the patients $123(42.1 \%)$ had received a diagnosis $<1$ year prior to inclusion. The main methods used for diagnosis included patient history $(242 ; 82.9 \%)$, stress electrocardiogram (ECG, 182, 62.3\%), coronary angiography $(172,58.9 \%)$, clinical signs (157, 53.8\%), ECG (142, 48.6\%) and myocardial scintigraphy (43, $14.7 \%$ ). Thus, for most patients several methods had been used. Any use of coronary angiography, not necessarily related to first diagnosis, was reported by 257 patients $(88.0 \%)$, in 167 cases $(57.2 \%)$ including revascularization. Risk factors included a history of smoking (96 patients; $32.9 \%$ ), hypertension (243; $83.2 \%)$, hyperlipidemia $(225 ; 77.1 \%)$, obesity (117; $40.1 \%)$, diabetes mellitus $(92 ; 31.5 \%)$ and family disposition $(64 ; 21.9 \%)$. Comorbidities such as heart failure $(94 ; 32.2 \%)$, arrhythmia $(91 ; 31.2 \%)$, chronic kidney disease $(68 ; 23.3 \%)$, depression $(66 ; 22.6 \%)$ and hyperuricemia $(46 ; 15.8 \%)$ were common.

Of the patients $147(50.3 \%)$ reported to be physically inactive; 100 patients $(34.2 \%)$ performed exercise at least twice a week. Walking and hiking were the most frequently reported exercises (133; 45.5\%), followed by endurance training $(13 ; 4.5 \%)$. All other kinds of training were reported by less than $5 \%$ of patients. Of the patients $231(79.1 \%)$ provided an estimate of their individual stress level on a 1-10 scale, reporting an average level of $4.7 \pm 2.3$.

Information on known triggers of AP attacks were available for all patients. Physical stress was reported
Table 1 Demographic and baseline features of the participants

\begin{tabular}{|l|l|}
\hline Total number of participants $(n ; \%)$ & $292 ; 100.0 \%$ \\
\hline Male participants $(n ; \%)$ & $162 ; 55.5 \%$ \\
\hline Age $(\mu \pm$ SD; min-max $)$ & $73.6 \pm 10.6 ; 24-96$ years \\
\hline Weight $(\mu \pm$ SD; min-max $)$ & $79.9 \pm 13.7 ; 49-125 \mathrm{~kg}$ \\
\hline Height $(\mu \pm$ SD; min-max) & $169.2 \pm 8.6 ; 147-190 \mathrm{~cm}$ \\
\hline Smoking behavior $(n ; \%)$ & \\
\hline Smoker & $41 ; 14.0 \%$ \\
\hline Former smoker & $55 ; 18.8 \%$ \\
\hline Non-smoker & $196 ; 67.1 \%$ \\
\hline Time since diagnosis $(n ; \%)$ & \\
\hline$<1$ year & $123 ; 42.1 \%$ \\
\hline 1-4 years & $70 ; 24.0 \%$ \\
\hline 4-7 years & $35 ; 12.0 \%$ \\
\hline$\geq 7$ years & $58 ; 19.9 \%$ \\
\hline Revascularization & $167 ; 57.2 \%$ \\
\hline Diabetes & $92 ; 31.5 \%$ \\
\hline Hypertension & $243 ; 83.2 \%$ \\
\hline Hyperlipidemia & $225 ; 77.1 \%$ \\
\hline
\end{tabular}


Table 2 Dosing of ranolazine at visit 1, visit 2 and after the study

\begin{tabular}{|c|c|c|c|}
\hline Dosage & $\begin{array}{l}\text { Visit } 1 \\
n(\%)\end{array}$ & $\begin{array}{l}\text { Visit } 2 \\
n(\%)\end{array}$ & $\begin{array}{l}\text { Future use } \\
n(\%)\end{array}$ \\
\hline $375 \mathrm{mg}$ & 254 (87.3) & 133 (49.1) & $132(50.0)$ \\
\hline $500 \mathrm{mg}$ & 34 (11.7) & 99 (36.5) & $93(35.2)$ \\
\hline $750 \mathrm{mg}$ & $3(1.0)$ & $39(14.4)$ & 39 (14.8) \\
\hline Total & $291(100.0)$ & $271(100.0)$ & $264(100.0)$ \\
\hline
\end{tabular}

most frequently $(270 ; 92.5 \%)$, followed by mental stress $(129 ; 44.2 \%)$, changing weather $(77 ; 26.4 \%)$ and exposure to cold or wind $(68 ; 23.3 \%)$. Other triggers occurred in $<10 \%$.

\section{Substance exposure}

Ranolazine was administered according to therapeutic needs, whereby an expected improvement of exercise tolerance in everyday life $(84.2 \%)$ and a reduction of angina $(83.2 \%)$ were the most common reasons. Other treatment objectives included anginal attacks despite antianginal premedication $(77.1 \%)$, reduction of fastacting nitroglycerin preparations $(28.8 \%)$ and the impossibility of revascularization (30.8\%); a full list is shown in Supplement Table 1. Of the patients 281 patients $(96.2 \%)$ received ranolazine twice daily, 10 patients $(3.4 \%)$ once daily, no dosing information was available in 1 case, 254 patients $(87.3 \%$ of those with data available) received the recommended starting dose of $375 \mathrm{mg}$, whereas 37 patients (12.7\%) started with a higher dose compared to the SmPC. During the course of the study, any kind of dose change was reported for 116 patients $(40.7 \%$ of those with data available), while 169 patients (59.3\%) continued the dose prescribed at baseline. Among those patients for whom ranolazine was prescribed after the completion of the study, $132(50.0 \%)$ received a dose of $375 \mathrm{mg}$ according to the physician's judgement (Table 2), including cases of repeated dose changes. After visit 2, 276 patients $(95.5 \%)$ continued and 13 patients $(4.5 \%)$ discontinued treatment. Reasons for discontinuation included lack of efficacy in four cases, and adverse events in three cases. In six patients, discontinuation occurred for other reasons.

At baseline, 290 patients $(99.3 \%)$ reported the use of cardiovascular medication other than ranolazine, and 156 patients $(53.4 \%)$ received additional concomitant medication for the treatment of any comorbidities (Table 3). In total over 50 different medications have been listed to treat a wide range of different comorbidities in participating patients. During the study, changes in concomitant cardiovascular medications were reported for 46 patients (15.9\%), and changes in general concomitant medication for 4 patients (1.4\%). The most frequent medications comprised acetylsalicylic acid (169 patients; 57.9\%), bisoprolol (118; $40.4 \%)$, glyceryl trinitrate $(93 ; 31.9 \%)$, simvastatin (83; $28.4 \%)$, nicorandil $(77 ; 26.4 \%)$ and atorvastatin $(75$; $25.7 \%$ ). All other medications were prescribed to $<25 \%$ of the patients. Itemized to ATC2, antianginal drugs were by far the most commonly used medication (336 prescriptions comprising 22 different drugs to $115.1 \%$ of the patients), followed by beta blockers (225 prescriptions comprising 20 drugs; $77.05 \%$ ) and renin angiotensin aldosteron system (RAAS) inhibitors (200 prescriptions of 25 drugs; $68.49 \%$ ). Of note 47 patients received CCB, of those 35 in combination with beta blockers. While acetylsalicylic acid was the most frequently mentioned co-medication, other antiplatelet therapies have been used in 49 patients. Of those, 23 patients combined acetylsalicylic acid and other antiplatelet therapies and 32 patients were treated with anticoagulants.

Table 3 Concomitant medication itemized to substance classes

\begin{tabular}{|l|l|l|}
\hline Medication class & $\begin{array}{l}\text { Number of prescriptions } \\
n(\%)\end{array}$ & Number of drugs \\
\hline RAAS inhibitors & $200(68.5)$ & 25 \\
\hline Ca antagonists & $52(17.8)$ & 9 \\
\hline Beta blocker & $225(77.1)$ & 20 \\
\hline Antihypertensive combination & $35(12.0)$ & 19 \\
\hline Diuretics & $65(22.3)$ & 17 \\
\hline Antianginal drugs & $336(115.1)$ & 22 \\
\hline Antithrombotics & $141(48.3)$ & 10 \\
\hline Other medications & $496(169.9)$ & 134 \\
\hline Total & $1550(530.8)$ & 256 \\
\hline RAAS Renin angiotensin aldosteron system & & \\
\hline
\end{tabular}




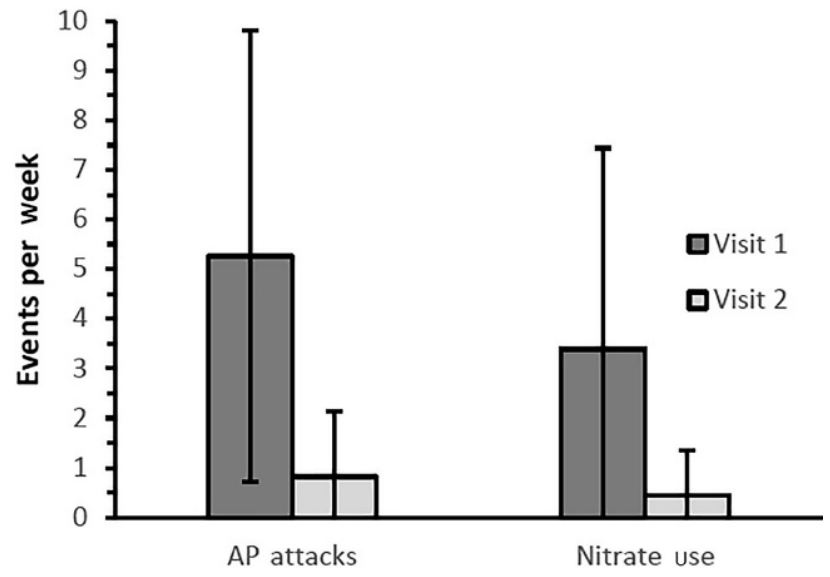

Fig. 1 AP attacks and nitrate use per week reported at both visits (arithmetic mean $\pm S D$ )

\section{Treatment outcome}

During the study period of 12 weeks, the number of angina attacks decreased significantly from $5.3 \pm 4.5$ to $0.8 \pm 1.3$ per week $(p<0.001)$. The frequency of nitrate use was used as a second measure for disease activity and a significant decrease from $3.4 \pm 4.1$ to $0.4 \pm 0.9$ applications per week was found (Fig. 1). An improvement of exercise capacity and a reduction of AP symptoms was reported by 266 patients $(94.0 \%$ and $93.7 \%$, respectively). Reduction in disease impact was confirmed by changes in CCS grading (Fig. 2). At visit 1, the majority of patients $(269,92.1 \%)$ were classified as CCS II and III, and $11(3.8 \%)$ as CCS IV. At visit 2, no patient was assessed as CCS IV, and the majority of 159 patients $(56.2 \%)$ as CCS I.

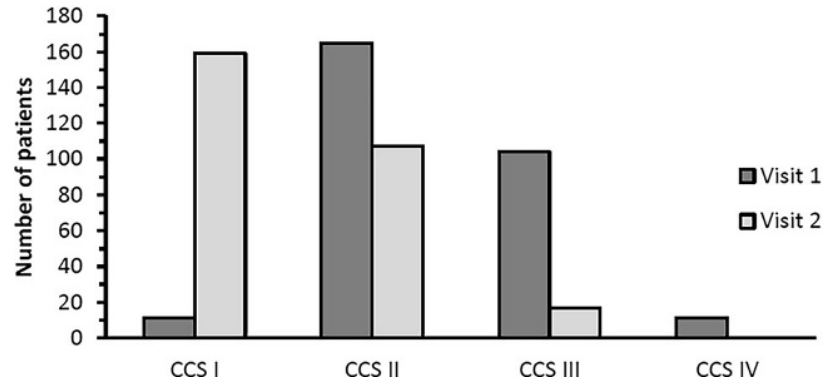

Fig. 2 CCS grading in the course of the two visits

Heart rate, systolic and diastolic blood pressure showed a trend towards reduction. These changes were statistically significant (not shown) but not assessed as clinically relevant (Table 4). Further changes from visit 1 to visit 2 on several scales were reflected by an increase of QoL, by both physicians and patients (Fig. 3) by using a 10 (poor QoL) -1 (excellent QoL) scale. At visit 1, the average assessment was $5.7 \pm 1.8$ by physicians and $6.1 \pm 2.0$ by patients. At visit 2 , this rating had improved to $3.0 \pm 1.7$, as equally assessed by physicians and patients. $(p<0.001$ for both physicians and patients).

A post hoc analysis revealed limited differences between various subgroups based on demographic or disease characteristics (Table 5). Particular benefits were experienced by the subgroup with potential atrial fibrillation $(n=33)$, as estimated by the use of anticoagulants in patients who presented with arrhythmia in the medical history, where the number of angina attacks per week dropped by 7.7, compared to the subgroup without atrial fibrillation $(n=256)$, where the decrease was 4.0. This difference was

Table 4 Vital signs in the course of both visits

\begin{tabular}{|c|c|c|c|c|c|c|}
\hline & \multicolumn{3}{|l|}{ Visit 1} & \multicolumn{3}{|l|}{ Visit 2} \\
\hline & Heart rate (bpm) & $\begin{array}{l}\text { Systolic blood pressure } \\
(\mathrm{mm} \mathrm{Hg})\end{array}$ & $\begin{array}{l}\text { Diastolic blood } \\
\text { pressure }(\mathrm{mm} \mathrm{Hg})\end{array}$ & Heart rate (bpm) & $\begin{array}{l}\text { Systolic blood } \\
\text { pressure }(\mathrm{mm} \mathrm{Hg})\end{array}$ & $\begin{array}{l}\text { Diastolic blood } \\
\text { pressure }(\mathrm{mm} \mathrm{Hg})\end{array}$ \\
\hline Min & 47 & 100 & 50 & 42 & 100 & 56 \\
\hline Max & 108 & 180 & 120 & 99 & 164 & 108 \\
\hline Median & 72 & 138 & 80 & 70 & 130 & 80 \\
\hline Mean & 72.5 & 137.3 & 80.8 & 69.5 & 130.7 & 78.7 \\
\hline SD & 11.6 & 16.1 & 10.3 & 9.5 & 12.4 & 8.0 \\
\hline$N$ & 290 & 292 & 292 & 286 & 285 & 285 \\
\hline
\end{tabular}

Fig. 3 Quality of life at both visits on a Likert scale from 1-10 scale classified by physician (a) and patient (b)
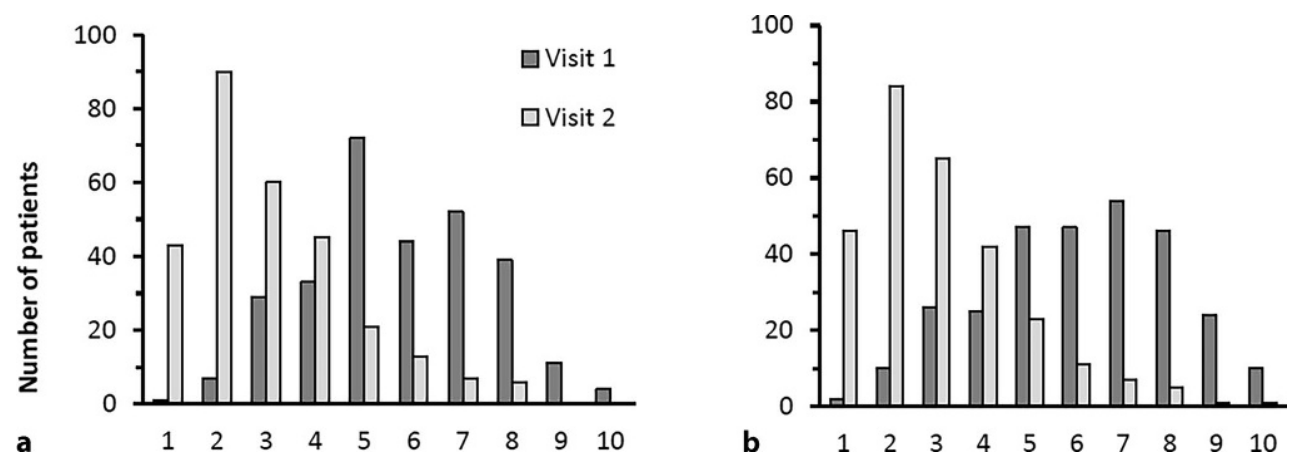
Table 5 Treatment outcome in various subgroups assessed by reduction $(\Delta)$ in AP attacks per week

\begin{tabular}{|c|c|c|c|c|}
\hline Subgroups & $\Delta \mathrm{AP}$ attacks & $N^{\mathrm{a}}$ & & \\
\hline Male vs. female & -4.5 vs. -4.4 & 161 & vs. & 125 \\
\hline Diagnosis $<1$ year vs. $\geq 1$ year & -4.1 vs. -4.8 & 123 & vs. & 160 \\
\hline Meteorosensitivity present vs. absent & -4.9 vs. -4.1 & 115 & vs. & 174 \\
\hline Beta blocker and CCB vs. beta blocker or CCB & -3.9 vs. -4.5 & 46 & vs. & 196 \\
\hline $\mathrm{CAD}^{\mathrm{b}}$, macrovascular vs. microvascular disease & -4.7 vs. -4.3 & 97 & vs. & 192 \\
\hline Atrial fibrillation ${ }^{\mathrm{C}}$ probable vs. improbable & -7.7 vs. -4.0 & 33 & vs. & 256 \\
\hline Type 2 diabetes mellitus, present vs. absent & -5.5 vs. -4.1 & 92 & vs. & 183 \\
\hline
\end{tabular}

Table 6 ADRs ${ }^{\text {a }}$ reported in the course of ARETHA AT

\begin{tabular}{|l|l|l|l|l|}
\hline Patient & Original Description & SOCs & Intensity & Relationship \\
\hline 1 & Occasional reflux gastritis & Gastrointestinal disorders & Mild & Possible \\
\hline 2 & Nausea & Gastrointestinal disorders & Moderate & Probable \\
\hline 2 & Vertigo & Ear and labyrinth disorders & Moderate & Probable \\
\hline 3 & Liver function levels raised & Investigations & Mild & Possible \\
\hline 3 & Renal function tests raised & Investigations & Mild & Possible \\
\hline $\begin{array}{l}\text { a ADR adverse drug reaction } \\
{ }^{\mathrm{b}} \text { SOC } \text { system organ classification }\end{array}$ & & & \\
\hline
\end{tabular}

highly significant $(p=0.005)$. The same was true for the subgroup with type 2 diabetes mellitus (92 patients, $31.5 \%$ ), where the decrease was 5.5 attacks per week, compared to 4.1 in the subgroup without diabetes $(p=0.002)$.

\section{Safety}

During the study period five ADRs were reported affecting 3 patients (1.04\%). None of these events was serious or clearly related to ranolazine (Table 6).

\section{Discussion}

\section{Limitations of the study}

As a non-interventional study, ARETHA AT exhibits specific limitations, including:

- The study was not conducted in a controlled environment; no randomization was performed, no control or placebo group was present and the patients were exposed to a multitude of other therapeutic procedures. Therefore, the observed improvements are not necessarily related to the administration of ranolazine; however, concomitant cardiovascular therapies were constant in $84.1 \%$ of the patients. Thus, uncontrolled external factors seem to exhibit only limited influence.

- 292 participants represent $40.6 \%$ of the maximum number of 720 patients; however, this number was not determined by formal sample size estimation and is therefore irrelevant for the descriptive char- acter of the results. The 292 patients are roughly equal to $0.1 \%$ of 250,000 patients in Austria suffering from stable AP [8].

- Subgroups were formed post hoc, recruitment did not aim at specific proportions for each subgroup; however, the results of the subgroup comparisons are in good accordance with the available literature.

- In the subgroup with patients with atrial fibrillation the diagnosis was not confirmed by an ECG.

- Participants were recruited at practices for primary care and by internal specialists, not at hospitals. Thus, extremely severe cases might have been underrepresented.

- There was no standardized test to measure the improvement in exercise capacity.

\section{Generalizability}

The ARETHA AT study focused on the situation of patients with stable angina in Austria. Demographic features were in good accordance with the results of a recent registry [6]. Austrian patients were not included in ranolazine registration studies and ARETHA AT patients differed by inclusion and exclusion criteria from the restrictions of controlled studies. Patients from all major regions of Austria were recruited in ARETHA AT, therefore reducing the risk of geographical bias. In addition, the outcome data showed high levels of internal consistency and were in accordance with studies from other European countries, such as OSCAR [9], ARETHA DE [10] and CARISA [11]. In contrast to these studies, a high percentage of female patients were recruited which is a major strength of ARETHA AT, 
since most other approaches are significantly biased in favor of male participants. The ARETHA AT study captured data which had not been considered consistently in the studies cited, including CCS grading, QoL estimates, trigger factors, comorbidities, methodical aspects of the first diagnosis, thus achieving a highly integrated view on the situation of the patients. These data may exclusively represent the situation in Austria, since no comparison is possible yet; however, these results are in accordance with observations from a different geographical region, the Commonwealth of Independent Nations [12]. Thus, a considerably degree of generalizability as well as validity of data can be assumed in spite of all weaknesses unavoidably connected with non-interventional studies. Furthermore, the ARETHA AT study considered the subjective wellbeing of the patients in addition to clinical endpoints, such as reduction in angina attacks and use of nitrates, and found consistent evidence for improved QoL. This kind of evidence was rarely addressed for other treatment options [13-15].

\section{Interpretation}

Both the EMA (European Medicines Agency) approval and the applicable guidelines [2,4] recommend the use of ranolazine for stable AP patients with inefficient first-line treatment. In accordance with these guidelines, the participating physicians usually prescribed ranolazine in order to improve exercise capacity, reduce symptoms, and reduce angina despite other treatments. Although ranolazine treatment usually starts with the recommended dosage, many patients are not uptitrated but are given the starting dose throughout the treatment. Even without an increase in dose, a more pronounced improvement was found compared to CARISA [11], comparable to the results of ARETHA DE [10, 16]. The observational study OSCAR [9] achieved a higher percentage of patients reaching CCS I; however, the longer observation period of OSCAR compared to ARETHA AT potentially explains most of the differences.

It might be suggested that this improvement in spite of the omitted uptitration indicates that the observed changes were not causally related to ranolazine, in accordance to some early and highly critical reviews on ranolazine [17]. Ranolazine, however, was prescribed only if first-line treatment had failed or were not applicable. Thus, the consistent improvement found by ARETHA AT in spite of predominantly unchanged concomitant medication strongly suggests a causal relationship as the best explanation of these real-life observations. The effectiveness of ranolazine was further confirmed by comparison with studies on alternative treatment strategies. An analysis on the use of trimetazidine for the treatment of stable angina pectoris [18] resulted in a significant improvement of numerous scales as well but the reduction of angina attacks per week ( $-1.3-0,6$ vs. -4.5 for ranolazine) and nitrate use per week $(-1.4--0.5$ to 2.3 vs. -3.0 for ranolazine) were less pronounced compared to ARETHA AT. Ivabradine seems to be most effective in patients with a heart rate exceeding $70 \mathrm{bpm}[14,19]$, which were found in $50 \%$ of the ARETHA AT population. In addition, some important and highly debated trials [20-23] cast doubts on the prognostic impact of invasive revascularization as first-line therapy and underline the importance of optimizing medicinal treatment. Thus, the results of ARETHA AT may support the suggestion [24] that ranolazine should become an integral part of optimal medicinal treatment of CAD, especially due to its compatibility with many other drugs, even dronedarone.

Although some of the subgroups studied by ARETHA AT were relatively small, the usability of ranolazine for a wide range of patients was confirmed. Females were only poorly represented in previous studies [11]. The results of the ARETHA AT study suggest that ranolazine is equally suitable for both genders (compare also [25]). This finding is of specific relevance since the prevalence of a severely impaired coronary flow reserve leads to a higher mortality in female AP patients [26]. In patients with atrial fibrillation (as indicated by administration of oral anticoagulants), the reduction in AP attacks was far more pronounced than in other patients $(-7.7$ vs. -4.0). This finding is in accordance with previous studies $[27,28]$ and confirms atrial fibrillation as another comorbidity where ranolazine may be suitable. Furthermore, AP attacks decreased significantly more in the subgroup with type 2 diabetes mellitus than in other patients $(-5.5$ vs. -4.1$)$, in good accordance with other real-world data [10]. As shown in previous studies, ranolazine seems to reduce glycated hemoglobin (HbAlC) levels, thereby exerting a positive effect on diabetes itself [29-31]. Treatment of patients with angina and type 2 diabetes mellitus is considered as challenging [10], therefore supporting the use of ranolazine in patients with $\mathrm{CAD}$ and diabetes.

The safety of the treatment was confirmed by a low number of ADRs and a low number of early withdrawals or discontinuations. Within approximately 12 weeks, ranolazine was withdrawn in $4.5 \%$, compared with, e.g., $22.1 \%$ within 8 weeks of nicorandil [15]. No deterioration of vital signs was found but heart rate was lowered and systolic and diastolic blood pressure showed a trend towards improvement. These results have to be interpreted with caution because no standard method was defined in the protocol to measure the blood pressure and because the cardiovascular co-medication was changed in almost $16 \%$ of patients with a wide range of co-morbidities and comedications. Ranolazine is not known to affect hemodynamic parameters based on large controlled studies [32] (a study with aberrant results [33] used intravenous administration and is therefore hardly comparable); therefore, adaptations in concomitant medication or life style may be likely reasons for the small 
changes in hemodymanic parameters. A tendency towards lowering of blood pressure was observed during the trial, although it may have been influenced by other concomitant medication. Thus, the safety profile of ranolazine summarized in the recent literature $[10,24,34]$ is confirmed, and ranolazine can be considered as an important symptomatic therapy of CAD [34]. Subgroup analyses suggest that ranolazine can be used safely in patients with a wide range of comorbidities.

\section{Conclusion}

- Ranolazine uptitration as possible by the SmPC is not a frequent treatment option for Austrian patients; however, patients still exhibit improvement.

- Patients exposed to ranolazine experience improved quality of life.

- In patients with stable angina and concomitant type 2diabetes mellitus or potential atrial fibrillation a specific benefit of ranolazine may be expected.

- Ranolazine is equally suitable for both genders.

- Ranolazine is tolerable and carries a favorable safety profile with a low number of ADRs when used according to Austrian real-world standards

Acknowledgements Thanks are due to C. Eder and Dr. G. Zweiker for constant support. Statistical and writing assistance were provided by Softwaremanufaktur Grünberg \& Redl GmbH (A. Redl) and CW Research \& Management GmbH (Dr. W. Adlassnig). The authors wish to express their gratitude to all participating physicians. This study was financially supported by A. Menarini Pharma GmbH.

Funding Open access funding provided by Medical University of Vienna.

Conflict of interest R. Zweiker has relationships with following drug companies: Novartis, Servier, AstraZeneca, DaiichiSankyo, Amgen, Merck, Gebro, Sanofi, Boehringer, Abbott, Bayer and Menarini. These relationships include research grants, membership of scientific advisory boards, lecture activities and congress invitations. I. Lang has relationships with drug companies including AOPOrphan Pharmaceuticals, Actelion, Bayer-Schering, Astra-Zeneca, Menarini, Servier, Cordis, Medtronic, GSK, and Ferrer. In addition, to being investigator in trials involving these companies, I. Lang's relationships include consultancy service, research grants, and membership of scientific advisory boards. I. Lang had access to all study data and analyses, was involved in interpretation of data; writing of the paper and decision to submit for publication. I. Lang serves on the editorial board of the European Heart Journal, Thrombosis and Haemostasis, and Pulmonary Circulation. I. Lang is not sitting on a committee or organization that may benefit from publication of this paper. E. Wallner is employee of A. Menarini Pharma GmbH Austria. G. Delle-Karth has relationships with following drug companies: Astra Zeneca, Amgen, Bayer, Boehringer Ingelheim, Daiichi-Sankyo MSD, Pfizer, Sanof, and Menarini. These relationships include research grants, membership of scientific advisory boards, lecture activities and congress invitations. J. Aichinger and B. Metzler declare that they have no competing interests.
Open Access This article is distributed under the terms of the Creative Commons Attribution 4.0 International License (http://creativecommons.org/licenses/by/4.0/), which permits unrestricted use, distribution, and reproduction in any medium, provided you give appropriate credit to the original author(s) and the source, provide a link to the Creative Commons license, and indicate if changes were made.

\section{References}

1. McCullough PA. Coronary artery disease. Clin J Am Soc Nephrol. 2007;2:611-6. https://doi.org/10.2215/CJN. 03871106.

2. EMA. Ranexa: summary of product characteristics. London: European Medicines Agency; 2013.

3. Scirica BM, Morrow DA, Hod H, Murphy SA, Belardinelli L, Hedgepeth CM, et al. Effect of ranolazine, an antianginal agent with novel electrophysiological properties, on the incidence of arrhythmias in patients with non ST-segment elevation acute coronary syndrome: results from the Metabolic Efficiency With Ranolazine for Less Ischemia in Non ST-Elevation Acute CoronarySyndrome Thrombolysis in Myocardial Infarction 36 (MERLIN-TIMI36) randomized controlled trial. Circulation. 2007;116:1647-52. https:// doi.org/10.1161/CIRCULATIONAHA.107.724880.

4. MontalescotG, Sechtem U, AchenbachS, Andreotti F, Arden C, Budaj A, et al. ESC guidelines on the management of stable coronary artery disease: the Task Force on the management of stable coronary artery disease of the European Society of Cardiology. Eur Heart J. 2013;2013(34):2949-3003. https://doi.org/10.1093/eurheartj/eht296.

5. Federation of Austrian Social Insurance Institutions. Amtliche Verlautbarung der österreichischen Sozialversicherung: 71. Änderung des Erstattungskodex. Vienna: Hauptverband der österreichischen Sozialversicherungsträger; 2010.

6. Lang IM, Badr-Eslam R, Greenlaw N, Young R, Steg PG. Managementand clinicaloutcomeofstablecoronaryartery disease in Austria: results from 5 years of the CLARIFY registry. Wien Klin Wochenschr. 2017;129:879-92. https:// doi.org/10.1007/s00508-017-1248-1.

7. Pell G. Use and misuse of Likert scales. Med Educ. 2005;39:970. https://doi.org/10.1111/j.1365-2929.2005. 02237.x. author reply 971.

8. Pichler M. Symptomatische stabile Angina pectoris: Epidemiologie, therapeutische Option und innovative Therapieansätze. J Kardiol. 2006;13:4-5.

9. Alexopoulos D, Kochiadakis G, Afthonidis D, Barbetseas J, Kelembekoglou P, Limberi S, et al. Ranolazine reduces angina frequency and severity and improves quality of life: observational study in patients with chronic angina under ranolazine treatment in Greece (OSCAR-GR). Int J Cardiol. 2016;205:111-6. https://doi.org/10.1016/j.ijcard.2015.10. 180.

10. Diedrichs H, Wollenberg U, Schmerbach K, Limberg R, Schiffhorst G, ZeiherAM.Application of ranozalinein stable angina pectoris therapy (ARETHA): real-world data from an observational study. J Clin Exp Cardiolog. 2015;6:1-6.

11. Chaitman BR, Pepine CJ, Parker JO, Skopal J, Chumakova G, Kuch J, etal. Effects of ranolazine with atenolol, amlodipine, or diltiazem on exercise tolerance and angina frequency in patients with severe chronic angina: a randomized controlled trial. JAMA. 2004;291:309-16. https://doi.org/ 10.1001/jama.291.3.309.

12. Kosiborod M, Arnold SV, Spertus JA, McGuire DK, Li Y, Yue $\mathrm{P}$, et al. Evaluation of ranolazine in patients with type 2 diabetes mellitus and chronic stable angina: results 
from the TERISA randomized clinical trial (type 2 diabetes evaluation of ranolazine in subjects with chronic stable angina). J Am Coll Cardiol. 2013;61:2038-45. https://doi. org/10.1016/j.jacc.2013.02.011.

13. Lopatin YM, Rosano GMC, Fragasso G, Lopaschuk GD, Seferovic PM, Gowdak LHW, et al. Rationale and benefits of trimetazidine by acting on cardiac metabolism in heart failure. Int J Cardiol. 2016;203:909-15. https://doi.org/10. 1016/j.ijcard.2015.11.060.

14. Ferrari R. A step further with ivabradine: SIGNIFY (Study assessInG the morbidity-mortality beNefits of the If inhibitor ivabradine in patients with coronarY artery disease). Eur Heart J.2009;11:D19-D27.

15. IONA Study Group. Effect of nicorandil on coronary events in patients with stable angina: the Impact Of Nicorandil In Angina (IONA) randomised trial. Lancet. 2002;359:1269-75. https://doi.org/10.1016/ S0140-6736(02)08265-X.

16. Schmutzler H. Nicht-interventionelle Studie „ARETHA“: Anwendung von Ranolazin in der Therapie der stabilen Angina pectoris. Berlin: Berlin-ChemieAG;2014.

17. A.T.I. Arzneimittelinformation Berlin. Ranolazin (Ranexa) bei chronisch stabila Angina Pectoris. Arznei Telegr. 2009;40:26-7.

18. Szwed H, Sadowski Z, Pachocki R, Domzał-Bocheńska M, Szymczak K, Szydłowski Z, et al. The antiischemic effects and tolerability of trimetazidinein coronary diabetic patients. A substudy from TRIMPOL-1. Cardiovasc Drugs Ther. 1999;13:217-22.

19. Fox K, Ford I, Steg PG, Tendera M, Ferrari R. Ivabradine for patients with stable coronary artery disease and left-ventricular systolic dysfunction (BEAUTIFUL): a randomised, double-blind, placebo-controlled trial. Lancet. 2008;372:807-16. https://doi.org/10.1016/S01406736(08)61170-8.

20. Boden WE, O'Rourke RA, Teo KK, Maron DJ, Hartigan PM, Sedlis SP, et al. Impact of optimal medical therapy with or without percutaneous coronary intervention on long-term cardiovascular end points in patients with stable coronary artery disease (from the COURAGE Trial). Am J Cardiol. 2009;104:1-4. https://doi.org/10.1016/j.amjcard.2009.02. 059.

21. Al-Lamee R, Thompson D, Dehbi H-M, Sen S, Tang K, Davies J, etal. Percutaneous coronaryinterventionin stable angina (ORBITA): a double-blind, randomised controlled trial. Lancet. 2018;391:31-40. https://doi.org/10.1016/ S0140-6736(17)32714-9.

22. Alexander KP,WeiszG, PratherK, James S, MarkDB, Anstrom $\mathrm{KJ}$, et al. Effects of ranolazine on angina and quality of life after percutaneous coronary intervention with incomplete revascularization: results from the ranolazine for incomplete vessel revascularization (RIVER-PCI) trial. Circulation. 2016;133:39-47. https://doi.org/10.1161/ CIRCULATIONAHA.115.019768.

23. Weisz G, Généreux P, Iñiguez A, Zurakowski A, Shechter M, Alexander KP, et al. Ranolazine in patients with incomplete revascularisation after percutaneous coronary intervention (RIVER-PCI): a multicentre, randomised, doubleblind, placebo-controlled trial. Lancet. 2016;387:136-45. https://doi.org/10.1016/S0140-6736(15)00459-6.
24. Ambrosio G, Komajda M, Mugelli A, Lopez-Sendon J, Tamargo J, Camm J. Management of stable angina: a commentary on the European Society of Cardiology guidelines. Eur J Prev Cardiol. 2016;23:1401-12. https://doi.org/ $10.1177 / 2047487316648475$.

25. Mehta PK, Goykhman P, Thomson LEJ, Shufelt C, Wei J, Yang $\mathrm{Y}$, et al. Ranolazine improves angina in women with evidence of myocardial ischemia but no obstructive coronary artery disease. Jacc Cardiovasc Imaging. 2011;4:514-22. https://doi.org/10.1016/j.jcmg.2011.03.007.

26. Taqueti VR, Shaw LJ, Cook NR, Murthy VL, Shah NR, Foster $\mathrm{CR}$, et al. Excess cardiovascular risk in women relative to men referred for coronary angiography is associated with severely impaired coronary flow reserve, not obstructive disease. Circulation. 2017;135:566-77. https://doi.org/10. 1161/CIRCULATIONAHA.116.023266.

27. Miles RH, Passman R, Murdock DK. Comparison of effectiveness and safety of ranolazine versus amiodarone for preventing atrial fibrillation after coronary artery bypass grafting. Am J Cardiol. 2011;108:673-6. https://doi.org/10. 1016/j.amjcard.2011.04.017.

28. Tardif J-C, Ford I, Tendera M, Bourassa MG, Fox K. Efficacy of ivabradine, a new selective I(f) inhibitor, compared with atenolol in patients with chronic stable angina. Eur Heart J. 2005;26:2529-36. https://doi.org/10.1093/ eurheartj/ehi586.

29. Morrow DA, Scirica BM, Chaitman BR, McGuire DK, MurphySA, Karwatowska-ProkopczukE, et al. Evaluation of the glycometabolic effects of ranolazine in patients with and without diabetes mellitus in the MERLIN-TIMI 36 randomized controlled trial. Circulation. 2009;119:2032-9. https:// doi.org/10.1161/CIRCULATIONAHA.107.763912.

30. Sossalla S, Maier LS. Role of ranolazine in angina, heart failure, arrhythmias, and diabetes. Pharmacol Ther. 2012;133:311-23. https://doi.org/10.1016/j.pharmthera. 2011.11.003.

31. Timmis AD, Chaitman BR, Crager M. Effects of ranolazine on exercise tolerance and HbAlc in patients with chronic angina and diabetes. Eur Heart J. 2006;27:42-8. https://doi. org/10.1093/eurheartj/ehi495.

32. Khan SS, Cuttica MJ, Beussink-Nelson L, Kozyleva A, Sanchez C, Mkrdichian H, et al. Effects of ranolazine on exercise capacity, right ventricular indices, and hemodynamic characteristics in pulmonary arterial hypertension: a pilot study. Pulm Circ. 2015;5:547-56. https://doi.org/10. $1086 / 682427$.

33. MaierLS, LayugB, Karwatowska-ProkopczukE, Belardinelli L, Lee S, Sander J, et al. RAnoLazIne for the treatment of diastolic heart failure in patients with preserved ejection fraction: the RALI-DHF proof-of-concept study. Jacc Heart Fail. 2013;1:115-22. https://doi.org/10.1016/j.jchf.2012. 12.002.

34. Manolis AJ, Poulimenos LE, Ambrosio G, Kallistratos MS, Lopez-Sendon J, Dechend R, et al. Medical treatment of stable angina: a tailored therapeutic approach. IntJ Cardiol. 2016;220:445-53. https://doi.org/10.1016/j.ijcard.2016.06. 150.

Publisher's Note Springer Nature remains neutral with regard to jurisdictional claims in published maps and institutional affiliations. 